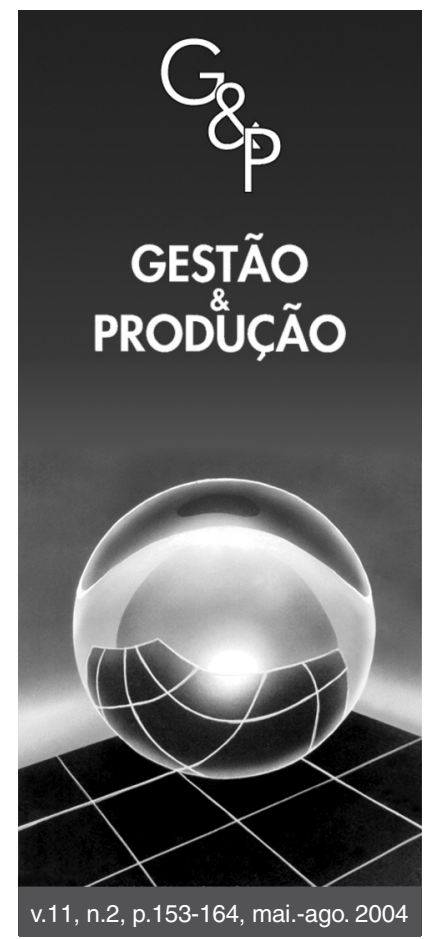

\title{
O USO DA FERRAMENTA GERENCIAMENTO POR CATEGORIA NA GESTÃO DA CADEIA DE SUPRIMENTOS: UM ESTUDO MULTICASO
}

\author{
Érica Ferreira Marques \\ Rosane L. Chicarelli Alcântara \\ Depto. de Engenharia de Produção, \\ Universidade Federal de São Carlos, \\ C.P. 676, CEP 13565-905, São Carlos, SP \\ e-mail: ericafmarques@ig.com.br \\ rosane@power.ufscar.br
}

Recebido em 16/3/2003 Aceito em 26/5/2004

\section{Resumo}

Diante do atual cenário competitivo, indústria e varejo estão buscando alternativas que garantam sua continuidade no mercado brasileiro. Para tanto, estão buscando atender eficientemente aos seus consumidores finais, oferecendo um mix de produtos adequado ao perfil de cada grupo de clientes. É dentro deste contexto que a ferramenta gerenciamento por categorias $(G C)$, e outras práticas do ECR, estão começando a fazer parte do dia-a-dia, da cultura e das estratégias dessas empresas. Este artigo, visando fornecer subsídios para compreender como o GC pode ser uma ferramenta que otimiza a eficiência na gestão da cadeia de suprimento, apresentará as principais ações a serem desenvolvidas para a implementação dessa ferramenta em pequenos e médios supermercados, suas características facilitadoras e limitadoras, bem como os critérios para a escolha do parceiro.

Palavras-chave: cadeia de suprimentos, canais de distribuição, ECR, gerenciamento por categorias, pequenos e médios supermercados.

\section{Introdução}

Para Bowersox e Cooper (1996), à medida que os mercados evoluem, os ciclos de vida dos produtos diminuem e, conseqüentemente, a concorrência se intensifica, havendo a necessidade da elevação dos custos para se manter um bom nível de serviço ao consumidor, pela disponibilização dos produtos no tempo e lugar exatos. Esses fatores têm obrigado os fornecedores e os demais membros dos sistemas de distribuição a procurarem estabelecer padrões de relacionamento mais cooperativos.

Dentro deste contexto, se antes o gerenciamento estratégico da sua cadeia de suprimentos era pouco relevante, principalmente para as empresas supermercadistas, atualmente, essas empresas vêm buscando reestruturar suas atuações no mercado com estratégias que consolidem uma maior interação entre elas e seus parceiros, bem como aderindo a um intenso programa de modernização, investindo em tecnologias de informação e comunicação (TICs).
A partir do momento em que os supermercados passam a utilizar as informações coletadas em seus terminais de pontos de vendas e repassam essas informações a seus fornecedores, visando reorganizar o fluxo de suprimento, de acordo com o que os clientes efetivamente compram e valorizam, percebem oportunidades de agregar valor a partir de um maior e mais adequado sortimento de produtos e serviços (Silva e Fischmann, 1999).

Observa-se, então, de acordo com alguns autores (Farina e Zylbersztajn, 1998; Zilber e Fischmann, 1999), uma crescente preocupação dos gestores, não apenas com a atividade empresarial exercida pela empresa e a sua interface com seus fornecedores e consumidores, mas também em adotar novas posturas ao valorizar a aplicação da ciência e da tecnologia nos negócios, assim como da qualidade da informação, da gestão mais cooperativa e da coordenação nos processos de produção, distribuição, circulação e consumo.

Para Kumar (1997), o setor supermercadista tem se tor- 
nado uma indústria com foco intensivo em tecnologia, tendo condições de gerenciar suas operações nas lojas e interagir com seus clientes, configurando a sua cadeia de suprimentos. Dentre elas, de acordo com Ghisi (2001), uma das que mais tem se destacado neste setor é o ECR (Efficient Consumer Response - Resposta Eficiente ao Consumidor).

$\mathrm{O}$ ECR, fundamentado em quatro pilares estratégicos de negócios (Sortimento Eficiente, Promoção Eficiente, Reposição Eficiente e Introdução Eficiente de Novos Produtos), visa melhorar a eficiência da cadeia de suprimentos através da padronização e racionalização dos processos, obtendo com isso a redução do tempo de entrega dos produtos adquiridos, a gestão das categorias de produto, o controle da demanda dos produtos com a automação do sistema de venda, bem como a agilização na troca de informações entre os supermercadistas e seus fornecedores (Ghisi, 2001; Moreira, 2001). Assim, a adoção dessas estratégias de negócios está sendo inserida aos poucos na cultura e nas estratégias das empresas, por meio de ações e atendimento junto aos pontos de venda.

Como uma das ferramentas do ECR, mais especificamnte relacionada à estratégia Sortimento Eficiente, o uso do Gerenciamento por Categoria (GC), pode proporcionar uma adequada combinação de produtos na loja, um aumento do giro dos produtos e da rentabilidade das categorias de uma loja, bem como uma visão mais completa sobre o perfil e os hábitos de compra dos consumidores, o que é fundamental para o processo de diferenciação e posicionamento competitivo no mercado. Para tanto, a sua implantação exige alto grau de parceria entre fornecedores e varejistas, envolvendo tecnologia de informação e, principalmente, uma mudança de comportamento das empresas varejistas.

Embora essa ferramenta de gestão possa oferecer atrativas oportunidades de negócio, existe ainda uma falta de conhecimento a respeito desse processo por parte de empresas supermercadistas em geral, e mais ainda das de pequeno e médio porte. Além disso, poucos estudos foram realizados sobre a implantação do GC em pequenos e médios supemercados.

Visando fornecer subsídios para compreender como o GC pode ser uma ferramenta que otimiza a eficiência na gestão da cadeia de suprimento, este artigo apresentará as principais ações a serem desenvolvidas para a implementação dessa ferramenta em pequenos e médios supermercados, suas características facilitadoras e limitadoras, bem como os critérios para a escolha do parceiro.

É válido ressaltar que os programas conjuntos de ação cooperativa entre o supermercado e os seus fornecedores devem ser a base para um sistema eficiente de abastecimento integrado, que consiga reduzir os custos logísticos e aperfeiçoar o serviço oferecido ao cliente final.

Para tanto, buscou-se responder às seguintes questões:

- Como os benefícios advindos do GC podem influenciar no processo à montante da cadeia de suprimentos?

- Quais as etapas a serem desenvolvidas no processo de adoção do GC?
- Quais são os agentes facilitadores e limitadores desse processo? e

- Quais são os critérios de seleção utilizados na escolha do parceiro?

A metodologia usada nesse trabalho teve como base uma pesquisa bibliográfica efetuada em publicações sobre Supply Chain Management (SCM), o processo de modernização do setor supermercadista, principalmente proposições teóricas da iniciativa do ECR e da ferramenta GC (objeto deste estudo). A seguir, múltiplos estudos de caso foram realizados, tendo-se o par supermercado/indústria (fornecedor) como unidade de análise.

A amostra tem o caráter não-probabilístico, escolhida com o uso da técnica de amostragem intencional ou por julgamento, já que as empresas, neste caso, teriam que se apresentar mais avançadas no que tange à prática da ferramenta foco deste estudo. Neste sentido, foram realizados três estudo de casos em supermercados de pequeno e médio porte e dois em indústrias alimentícias líderes em seu setor. Como critérios de seleção dos casos, foram estabelecidos a localização (todas sediadas no Estado de São Paulo), o tamanho das empresas varejistas (entre $250 \mathrm{~m}^{2}$ e $2.500 \mathrm{~m}^{2} / \mathrm{loja}$ ) e a adoção em si do processo de GC nas empresas.

Esses casos foram realizados entre novembro de 2001 e setembro de 2002 por meio de entrevista pessoal com os responsáveis pela gerência da categoria e outras pessoas envolvidas no processo, tanto do varejo quanto da indústria. Para tanto, foram utilizados dois questionários semi-estruturados, um direcionado ao varejo e outro à indústria, sendo que retornos telefônicos também foram utilizados quando necessário. Com estes questionários, buscou-se considerar a necessidade de conhecer a organização, as informações pertinentes à implementação do GC e como o uso desse processo pode influenciar positivamente na cadeia de suprimentos.

$\mathrm{O}$ artigo apresenta, além desta introdução, uma breve revisão da literatura sobre a gestão da cadeia de suprimentos e a sua importância, o ECR e o processo de GC, destacando sua função na cadeia de suprimentos. Posteriormente, apresentam-se as informações obtidas, de acordo com o que foi proposto nesta introdução, e em seguida as conclusões.

\section{Cadeia de suprimentos e ECR: as mudanças na gestão pela busca da eficiência}

\subsection{Supply Chain Management (SCM) e ECR}

De acordo com Figueiredo e Zambom (1998) e Hutt e Speh (2001), uma cadeia de suprimento compreende um sistema constituído por agentes tomadores de decisão envolvidos em um processo interdependente, que abrange todas as atividades associadas à movimentação de produtos e serviços, por meio de um fluxo em uma direção, envolvendo 
desde fornecedores de matéria-prima, a produção propriamente dita e distribuição, até consumidores finais. Ainda segundo Figueiredo e Zambom (1998), todos os elementos ou os níveis de uma cadeia executam funções importantes, cujos respectivos desempenhos determinam, de forma interdependente, o desempenho do sistema como um todo. A gestão deste conjunto de atividades é o que os autores Oliver e Webber, em seu trabalho desenvolvido em 1992 e intitulado "Supply Chain Management: logistics catches up with strategic", pioneiramente conceituaram de Supply Chain Management (SCM) ou Gestão da Cadeia de Suprimentos (Batalha e Silva, 2001).

Segundo Svensson (2002), SCM surgiu no início dos anos 80 como um resultado de rápidas mudanças e desafios na gestão de vários setores industriais. Para Batalha e Silva (2001), a necessidade de fornecer respostas mais rápidas às oportunidades de negócios está relacionada diretamente com a capacidade de coordenação entre as atividades de produção e de distribuição desenvolvidas pelas empresas, ao longo de uma cadeia de produção.

Esta necessidade de maior integração da cadeia de suprimentos está modificando a forma de se fazer negócios, estimulando os administradores a oferecerem seus produtos ou serviços aos seus clientes de maneira mais acelerada, mais barata e melhor que a da concorrência. Portanto, para ganhar competitividade, está evidente que isto não poderá ser conseguido isoladamente. Ao contrário, para serem bem sucedidos, os administradores precisam trabalhar de modo cooperativo com as melhores organizações de sua cadeia de suprimento e de forma a que os processos se tornem sincronizados (Zilber e Fischmann, 1999).

Segundo Porter (1986), a competitividade pressupõe a existência de organizações concorrentes que buscam atender a um determinado mercado. Desta forma, na maioria dos setores, uma característica central da concorrência é a que as empresas são mutuamente dependentes: elas sentem os efeitos dos movimentos das outras e tendem a reagir a eles. Portanto, é no nível de cada negócio individual ou setor industrial que a maior parte das interações competitivas ocorrem, obtendo-se ou perdendo-se vantagens competitivas.

Assim, Cooper et al. (1997) definem SCM como a integração de todos os processos da cadeia até o consumidor final, por meio de fornecedores que proporcionam produtos, serviços e informação que agregam valor aos seus clientes, o que diferencia o conceito de canal de distribuição.

Neste ponto do artigo, deve ser feita uma ressalva quanto aos agentes participantes e à fucionalidade de um canal de distribuição. Como agentes primários dos canais de distribuição, a indústria e o varejo são estruturas indispensáveis para o processo de distribuição, pois criam as utilidades de tempo, de lugar e de posse atendendo às necessidades da demanda. De acordo com Stern e El-ansary (1992), além dessa função de suprir os produtos e serviços no lugar certo, em quantidade, qualidade e preços adequados, para satisfazer uma demanda existente, as empresas participantes de um canal de distribuição devem agir, também, como agentes estimuladores dessa demanda. Ou seja, o canal deve ser visto como uma rede de empresas independentes que agem em sintonia, de forma a criar valor para o usuário final por meio da distribuição de produtos.

Silva (1999), então, destaca que, pela conceituação de canal de distribuição, todos os agentes ou intermediários se ocupam da condução do produto da indústria até o consumidor final, da melhor forma possível. No entanto, o conceito de cadeia de suprimentos tem um foco mais amplo, no qual abrange todos os elos da cadeia, inclusive fornecedores da indústria, fornecedores de insumos e indústrias de apoio para a cadeia como um todo. Além disso, o conceito de cadeia de suprimento visa à eficiência de todos os elos da cadeia, através da sincronização de todas as atividades de produção, de forma a reduzir custos, minimizar ciclos e maximizar o valor percebido pelo cliente final, por meio do rompimento das barreiras entre departamentos e áreas. Mas esta sincronização entre fluxo físico de produtos e fluxo de informações sobre necessidades do mercado pode ser, talvez, o grande desafio dos gestores.

Para tanto, os acordos entre fornecedores e distribuidores devem ter um caráter de longo prazo, facilitando as negociações, as promoções, reforçando o relacionamento de parceria dos membros da cadeia de suprimento (Wood Jr, 1998).

No caso dos supermercados, por exemplo, existe um amplo conjunto de antigas práticas que estão muito arraigadas, e que podem ser consideradas como barreiras ao bom andamento de projetos da cadeia de suprimento. Dentre estas práticas se destacam: o relacionamento com os fornecedores, ainda fortemente dominado pela política de queda de braço mensal com relação aos preços dos produtos, o recebimento direto da maioria dos produtos nas lojas, o que dificulta o controle do recebimento e a avaliação de desempenho dos fornecedores, a tecnologia de informação que, ainda, apresenta fortes deficiências, etc (Fleury, 1999).

Zilber e Fischmann (1999) também destacam a difícil questão da conciliação de interesses que, por vezes, são heterogêneos. $\mathrm{O}$ encadeamento de empresas, conforme o conceito de SCM, envolve as atividades logísticas internas e externas às empresas, desde os fornecedores e sub-fornecedores até o cliente final. Assim, as diferenças de estratégias e metas de cada uma destas empresas devem ser consideradas, permanecendo, contudo, uma percepção crítica para o seu sucesso que é a focalização no consumidor final.

Segundo Alcântara (1997), o grau de poder de cada elo influencia fortemente a composição da estrutura do canal. O surgimento e a consolidação das grandes cadeias supermercadistas no Brasil está concentrando o poder nesse elo em detrimento da indústria e, principalmente, do atacado, que passam a buscar alternativas estratégicas para sobreviver como membro do canal. Assim, verifica-se a vulnerabilidade de muitos fornecedores pela dependência excessiva de alguns grandes varejistas, que começam a impor suas condições de forneci- 
mento, definições de formas de abastecimento, bem como os procedimentos de gestão que a indústria deve adotar.

Desta forma, alguns fatores, como o avanço da tecnologia da informação, a necessidade de se chegar ao consumidor final o preço mais competitivo possível, bem como o surgimento de novas formas de relacionamento interorganizacionais, estão levando as empresas produtoras e os seus intermediários a repensar seu papel estratégico e sua atuação dentro da cadeia de distribuição.

De acordo com alguns autores (Chapman et al., 2000; Segre e Bastos, 2000), essa busca pelo aumento de eficiência, redução de custos e competitividade para prover maior valor agregado aos clientes, tem transformado o setor supermercadista e seus fornecedores e modificado suas formas de competição, principalmente sob três aspectos:

- Ganhos de produtividade - o uso das tecnologias de informação e comunicação eleva o grau de conhecimento do negócio e, por conseguinte, torna mais confiável o controle sobre as operações comerciais. Além disso, a integração pelas comunicações e a implantação de processos e sistemas padronizados dentro da empresa e entre empresas, via Redes Locais, Intranet, EDI (Electronic Data Interchange) e Internet, proporcionam a redução de custos com a supressão de erros e da duplicação de pedidos e cobranças, racionalizando os processos;

- Relacionamento entre a empresa e o fornecedor - o surgimento de grandes cadeias de supermercados tem modificado a forma de distribuição de mercadorias na sociedade. Hoje, a tendência é que a cadeia de distribuição coloque à disposição informações periódicas, que confiram aos fabricantes dos produtos facilidade maior de produzir aquilo que o consumidor espera encontrar nas lojas; e

- Relacionamento entre a empresa e o consumidor - as informações dos consumidores quanto às suas necessidades e preferências, coletadas por meio da informatização dos estabelecimentos, trazem para os supermercadistas a oportunidade de conhecimento de seus usuários. Com isso, tanto os supermercados quanto seus fornecedores ganham, agradando o cliente com um serviço adequado, focalizando a produção nos produtos mais solicitados e identificando novas demandas a serem desenvolvidas.

Segundo Aravechia e Pires (2000), para que seja possível gerenciar as empresas sob essa nova perspectiva, têm surgido várias práticas e ferramentas que visam, sobretudo, a obtenção de uma maior sinergia na gestão da cadeia produtiva, proporcionando a obtenção de maiores vantagens competitivas aos seus participantes. Para tanto, é fundamental que as unidades de negócio participantes da cadeia, apresentem um alinhamento das metas do negócio, ao longo de toda a cadeia, de maneira consistente e integrada. Para King e Phumpiu (1996), a análise da competitividade da cadeia de valor é um conceito fundamental na iniciativa do ECR, podendo este ser visto como uma forma de implementar o SCM.

O ECR é definido por vários autores (Salmon, 1993; Ho- ban, 1998; Kotzab, 1999) como uma estratégia de gestão no setor varejista. De uma forma mais completa, tem-se que é "uma estratégia em que o varejista, o distribuidor e o fornecedor trabalham muito próximos para eliminar custos excedentes da cadeia de abastecimento e melhor servir ao consumidor. Por meio do foco de integrar os processos logísticos e comerciais ao longo de toda a cadeia de suprimento, em vez da eficiência individual das partes, pode-se obter benefícios significativos quanto à diminuição dos custos operacionais e administrativos, redução dos níveis e dos custos de manutenção dos estoques, otimização da produção, incremento em vendas e melhorias na relação indústria/varejo" (ECR Brasil, 1998a, p. 13).

Na visão do ECR, de acordo com Dib (1997) e Ghisi (2001), o consumidor dá início ao processo de reposição, no momento em que são registradas suas compras no ponto de venda (PDV). As informações são compartilhadas entre os elos da cadeia em tempo real, que melhor conseguem se ajustar às reais necessidades dos consumidores. O sistema que sustenta o ECR é um misto entre o sistema "puxado" (pull) e o sincrônico, já que, quando o pedido do cliente é feito, este é transmitido imediatamente para o fornecedor por meio do uso de tecnologia de informação. Entretanto, uma crítica a esse modelo é que os fornecedores têm que responder, em um tempo muito curto, às necessidades dos clientes.

Segundo Kinsey e Ashman (2000), o ECR é formado, basicamente, por dois componentes - tecnologia e relacionamento (parceria), sendo considerados também como os maiores problemas na sua implementação. A tecnologia pode ser representada pela adoção de EDI, recebimento eletrônico, análises de movimentação de produtos, reposicionamento baseado em scanners, e o uso de planogramas (representação gráfica dos espaços de gôndola e frentes para itens individuais, que compõe uma categoria inteira ou seção de loja) para alocação de espaço nas gôndolas. Já o outro componente (relacionamento) reflete em decisões compartilhadas entre os parceiros no que tange a preço, propaganda, alocações de espaço e promoções.

Desta forma, o verdadeiro objetivo do ECR é a criação de um sistema eficaz, no qual distribuidores e fornecedores trabalhem em conjunto como aliados comerciais, produzindo um fluxo contínuo de produtos adequado ao consumo, tendo como base a tecnologia de informação, a fim de maximizar a satisfação do consumidor e minimizar custos e inventário (King e Phumpiu, 1996; Kurnia e Johnston, 2001). Para tanto, essa iniciativa está baseada na união de quatro processos que fluem no canal de suprimento inteiro: sortimento eficiente de loja, reposicionamento eficiente, promoção eficiente e introdução de novos produtos.

De acordo com Kurnia et al. (1998), estas estratégias são suportadas por dois processos (Gerenciamento por Categorias e Programa de Reposição Contínua) e habilitada por cinco tecnologias (Código de barras/Scanners, EDI, ABCCusteio Baseado em Atividades, Pedido Ordenado por Computador e Cross Docking). 


\subsection{0 papel do Gerenciamento por Categoria (GC)}

Berry (1999, p. 58) quando analisa o futuro do varejo, diz que "os tempos da concorrência simples, baseada no preço, estão ficando para trás. Daqui para frente, os varejistas deverão se adequar ao modelo de criação de valor para os seus clientes, o que implica em maximizar benefícios valiosos, minimizar os custos, e adotar algum diferencial em relação aos concorrentes, diferencial esse que esteja em mutação para não ser imitado".

Dentre as decisões operacionais pertinentes à atividade varejista, como layout, ambientação e exposição dos produtos de uma forma que agrade os clientes, são fundamentais as relacionadas à disposição dos produtos nas gôndolas. De acordo com alguns autores (Desmet e Renaudin, 1998; Cesarino e Caixeta Filho, 2002), frente às limitações de espaço interno, o arranjo encontrado para a distribuição dos produtos não somente vai influenciar diretamente as vendas de cada loja, como também pode significar um componente importante da estrutura de custos do supermercado. Por outro lado, é crescente a necessidade de personalização dos serviços do varejo, ou seja, o consumidor exige um sortimento adequado de produtos e um atendimento cada vez mais direto.

Dentro deste contexto, tem-se como um exemplo a prática da ferramenta Gerenciamento por Categorias, que é considerada elemento central da estratégia Sortimento Eficiente.

O termo Gerenciamento por Categorias surgiu em 1987 quando algumas empresas, como Procter \& Gamble e CocaCola, começaram a substituir o modo de gestão por "marcas" para gestão por "categorias", visando otimizar o mix de produtos (Hutchins, 1997; Harris et al., 1999). Neste processo, produtos individuais de vários fornecedores são agrupados em categorias, que passam a ser gerenciadas como unidades estratégicas de negócios, de uma forma que os consumidores percebam ser inter-relacionadas ou substituíveis na satisfação de suas necessidades (King e Phumpiu, 1996; Hogarth-Scott e Dapiran, 1997; ECR Brasil, 1998).

Para os supermercadistas, o GC pode ser apontado como uma ferramenta que proporciona a fidelização de seus consumidores com a criação de valor para seus clientes e um diferencial em relação à concorrência. Isso porque, de acordo com Dib (1997), essa ferramenta visa obter uma ótima composição das diversas categorias de produto da loja e da composição de produtos dentro da categoria, além da aquisição de uma visão mais completa sobre o perfil e os hábitos de compra dos consumidores. Para tanto, o GC envolve a comunicação muito próxima e a cooperação entre várias áreas funcionais tanto dos varejistas quanto de seus fornecedores (Hogarth-Scott, 1999).

Essa relação de parceria é estabelecida a partir do momento em que o varejista não tendo total condição de gerenciar todas as categorias de forma eficiente (em um supermercado pode ter até mais de 250 categorias, por exemplo), busca fazer alianças estratégicas com os fabricantes (indústrias). Por sua vez, as indústrias se encontram em uma posição melhor por conhecer a categoria em que atuam seus produtos (especialização), por ter know-how em reunir dados e transformá-los em informação, por ter condições de realizarem pesquisas de mercado para aumentar o conhecimento do comportamento do consumidor, além de possuir alguns recursos analíticos e tecnológicos que o varejo não possui, tais como software para gestão de espaço nas gôndolas, de promoção, e de otimização de mercadorias (Category Management, 1995). Desta forma, o varejo pode beneficiar-se pela utilização desses recursos, e a indústria, parceira envolvida no processo, poderá ter um melhor entendimento do consumidor quanto ao seu hábito de uso, posicionamento e imagem da categoria de seus produtos.

De acordo com ECR Brasil (2001), para se pôr em prática a implementação do processo, é preciso seguir alguns passos fundamentais:

1. Preparação interna, em que tem de haver um alinhamento com a diretoria, definição de uma equipe dedicada especificamente para o gerenciamento, organização da informação e tecnologia;

2. Seleção do capitão da categoria, que é a indústria escolhida pelo varejista para gerenciar a categoria completa, incluindo as marcas concorrentes, sendo ele o co-responsável junto com o varejista pelo monitoramento dos resultados. Nesse processo de parceria, a indústria capitão da categoria pode apontar alguns problemas da categoria para o varejista, buscando convencê-lo das necessidades de adaptações, melhorias e mudanças na forma com que este utiliza as ferramentas do GC. De forma idealizada, Ghisi (2001) afirma que essa indústria deve, acima de tudo, atuar de forma a maximizar o desempenho da categoria e não defender o seu produto ou criticar os dos concorrentes diretos que atuam em uma mesma categoria. Caso isso ocorra, de acordo com o mesmo autor, pode haver um impacto negativo na própria relação de negócio, colocando em jogo a credibilidade do trabalho em conjunto desenvolvido;

3. Definição do contrato de confidencialidade, com a oficialização da parceria entre indústria e varejo, valorizando a ética e a imparcialidade; e

4. Reunião Inicial, onde há a definição, pelos parceiros, das diretrizes sobre a escolha da categoria a ser trabalhada, a estratégia associada e o cronograma de trabalho. É importante compartilhar as expectativas, visão estratégica sobre a categoria e definir conjuntamente os objetivos do plano.

Segundo ECR Brasil (1998) e Rojo (2001), o GC está fundamentado em seis componentes-chaves:

- Cartão de Metas: São ferramentas para definir, medir e monitorar o desempenho da categoria em relação aos objetivos estabelecidos. Abrangem medidas de desempenho internas e externas;

- Informática: O GC está baseado no uso intensivo de tecnologia da informação visando o apoio às decisões, o planejamento, análise e controle de desempenho da categoria;

- Capacidade da Organização: A capacidade organizacional 
é ponto chave para a implementação desta ferramenta, pois define as funções dos gestores das categorias e o entrelaçamento destes no organograma da empresa. Para isso, é importante que haja o envolvimento da alta direção, a clara definição de responsabilidades, o conhecimento da ferramenta pelos envolvidos no processo, a estrutura organizacional com apoio para as análises de dados, a orientação para resultados e o desenvolvimento e treinamento intensivo de pessoal;

- Parceria: O GC está baseado em forte e efetiva parceria entre o varejista e fornecedores. Alguns varejistas obtêm apoio de um fornecedor para ajudá-lo a gerenciar uma categoria. Conhecido como capitão da categoria, esse fornecedor compõe uma aliança com o varejista para ajudá-lo a obter informações sobre o consumidor e o mercado, visando melhorar o desempenho e o lucro potencial da categoria;

-Estratégia: Com pensamento estratégico, a empresa deve buscar uma orientação de esforços para oferecer "valor" aos consumidores, o comprometimento da alta direção, o gerenciamento das categorias como unidades estratégicas de negócios e a definição de uma estratégia de marketing, abastecimento e relacionamento com o fornecedor; e

- Processo: O processo de negócios do GC é um conjunto estruturado de atividades em etapas, projetado para o desenvolvimento e implementação de um Plano de Negócios de uma categoria. A metodologia utilizada para implantação do Plano está baseada em oito etapas, conforme mostra a Figura 1.

Ressalta-se que não é necessário o cumprimento desses oito passos para realização de um processo de GC, até porque a realidade organizacional é diferente para cada empresa envolvida, mas é importante avaliar o nível de profundidade, investimento e tempo, que são as variáveis do processo. Além disso, como a realização de processos de GC entre parceiros comerciais é uma decisão estratégica, é necessário que mudanças nas atitudes de trabalho aconteçam, começando com a comunicação entre os parceiros, preparação de toda a equipe, disponibilidade de informações sobre dados de venda e mercado, receptividade a sugestões e críticas, bem como a confiança no processo e no parceiro (ECR Brasil, 2001).

Desta forma, para garantir a consolidação dessa ferramenta entre as organizações, há algumas premissas importantes que devem ser expostas, como o forte comprometimento do primeiro nível das empresas, relacionamento de confiança e transparência, definição de uma liderança do processo, definição de uma equipe de trabalho multifuncional com a participação de pessoas de todas as áreas envolvidas no projeto, intensa troca de dados e informações entre as empresas, investimento em pesquisa com o consumidor e tecnologia de informação, e, principalmente, a adequação de um plano de gerenciamento conforme a realidade de cada loja (Category Management, 1995; ECR Brasil, 2001).

Com a implantação dessa ferramenta e o desenvolvimento de um relacionamento mais cooperativo e estratégico entre as empresas, esperam-se alguns benefícios tais como: o retorno nas ações promocionais por meio de um calendário mais eficiente e adequado à realidade do supermercado e do consumidor, aumento da satisfação do consumidor pela oferta do mix mais adequado de produtos, preço e facilidade de compra através de um melhor layout da loja e da gôndola,

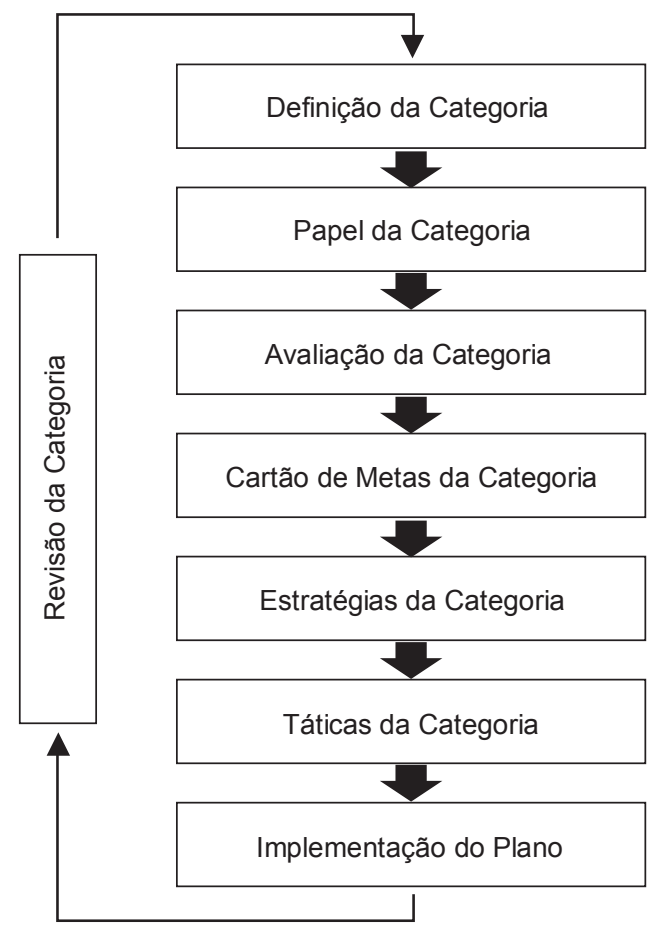

1- Define os produtos que formarão a categoria, e sua segmentação a partir da perspectiva do consumidor;

2- Define a prioridade e o papel da categoria para a loja e seu público-alvo, conforme a estratégia;

3- Analisa o desempenho da categoria (oportunidades de venda, lucro e retorno), examinando as informações sobre consumidores e mercado;

4- Define os objetivos a serem alcançados pelos varejistas e fornecedores;

5- Desenvolve as estratégias de mkt e de abastecimento de produtos para alcance das metas da categoria;

6- Determina as ações específicas (sortimento, preço, apresentação nas gôndolas, promoções) para atingir os resultados previstos na estratégia; e

7- Implementa um plano de negócios da categoria, mediante cronograma e atribuições de responsabilidades.

Figura 1. Metodologia do gerenciamento por categoria Fonte: ECR Brasil (1998, p. 49). 
incremento nas vendas, bem como aumento de rentabilidade da categoria (ECR Brasil, 2000).

Observa-se, então, dentro do contexto da cadeia de suprimentos, que esse processo enfatiza a geração efetiva da demanda nos pontos de venda, trabalhando com ferramentas que agregam valor ao consumidor, possibilitando um maior consumo de produtos e uma melhor análise da cadeia de suprimento quanto ao serviço logístico necessário e o custo de abastecimento. Dessa forma, espera-se aumentar a lucratividade de todos os participantes à montante da cadeia.

Entretanto, é preciso apontar algumas dificuldades para a sua implementação, que devem ser avaliadas e discutidas previamente para minimizar seus impactos. Esses obstáculos, geralmente, acontecem quando a gerência sênior não está comprometida com o gerenciamento da categoria; operações nos programas de estoque não executam os planos da categoria; critérios de avaliação e compensação do gestor da categoria não refletem nas metas da categoria; os planos da categoria não são revisados; papéis da categoria não direcionam o desenvolvimento das estratégias e táticas; poucos varejistas conhecem o comportamento, percepção e necessidades de seus consumidores; metas financeiras não correspondem sempre com as oportunidades descobertas durante o gerenciamento e o varejista não tem dados necessários para o gerenciamento da categoria (Category Management, 1995).

Ainda, em relação às dificuldades e obstáculos, podem ser apontados os sistemas ineficientes de informação do varejista para o fornecimento de dados; as dificuldades da indústria reunir dados que o varejista necessita; a limitada pesquisa proporcionada por parceiros no processo quanto ao comportamento de compra da categoria; transferência de dados em papel entre varejista e fornecedor; a falta de compartilhamento de dados e informações entre varejistas e fornecedores e as mudanças na consolidação promocional e introdução de novos produtos, tornando difícil manter os planos visados.

\section{Apresentação dos resultados}

Os dados apresentados a seguir são resultado de pesquisa realizada junto a três varejistas (supermercados de pequeno e médio porte) e duas indústrias de alimentos fornecedoras, líderes em seu setor, sendo que essas organizações foram escolhidas de acordo com os critérios já colocados.

$\mathrm{Na}$ escolha das empresas varejistas, partiu-se do princípio que algumas empresas de pequeno e médio porte já estão buscando conceitos de racionalidade de operações e fidelização de seus clientes. Poucas buscam isso utilizando algumas práticas do ECR para se manterem competitivas no mercado, e o número de adeptos desse segmento pode-se dizer que é, ainda, relativamente baixo se compararmos com as grandes redes.

São apresentadas, a seguir, informações referentes ao processo de implantação do GC nas empresas, sintetizadas de Marques (2003).

\subsection{Processo de implantação}

As empresas entrevistadas, tanto o grupo do varejo quanto o grupo das indústrias, iniciaram suas experiências em relação ao GC com projetos-piloto, antes de adotarem definitivamente essa forma de gestão, para verificarem os reais benefícios oriundos dessa ferramenta, e as dificuldades encontradas durante a fase de adaptação e implementação desse processo.

Para a realização desses projetos-piloto, houve a necessidade de participação de consultorias para implantação da metodologia (desenvolvida pelo ECR Brasil, só que adaptada a cada empresa), treinamento interno e preparação dos funcionários, já que compras, exposição nas gôndolas e layout passariam por mudanças com esse processo. O principal motivo alegado, que levaram as empresas (indústrias e varejos) a investirem nesse processo de gestão, foi a obtenção de oportunidades de negócios com as categorias de produtos, por um detalhamento de informações pertinentes às categorias e, também, por pesquisas junto aos consumidores. A caracterização das empresas pesquisadas e as informações pertinentes à implementação dos projetos-piloto serão abordados de forma consolidada no Tabela 1, sem a identificação das empresas, levando-se em consideração as questões diretamente relacionadas aos objetivos deste estudo.

Baseado nos principais componentes-chave de capacitação do GC (estratégia, processos, estrutura organizacional ou capacidade da organização, tecnologia), este estudo procurou analisá-los, uma vez que abrangem aspectos fundamentais para o sucesso da implantação do GC tanto na indústria como no varejo.

\section{a) Estrutura Organizacional}

Pelas entrevistas realizadas com as indústrias e empresas varejistas, para a adoção do processo de GC, constatou-se uma forte necessidade de:

- Criação de departamento para dar suporte ao processo (tanto indústria quanto varejo). Essa necessidade é mais crítica, principalmente, quando a empresa varejista tem a intenção de ampliar a adoção do GC para um número maior de lojas ou, até mesmo, ampliar o número de categorias gerenciadas como unidades estratégicas;

- Pessoas devidamente treinadas e com dedicação exclusiva para os projetos (se a empresa trabalha com um número alto de categorias gerenciadas, deve haver um número de pessoas bastante suficiente para coordenar esses grupos de categorias);

-Softwares especializados para geração de relatórios e análises variadas, e um banco de dados com os devidos códigos de barras (para não repetição e conflito de informações dos produtos);

- Mudanças internas nas lojas supermercadistas quanto ao layout e ambientação; e

- Pesquisas realizadas com os consumidores para obtenção das informações focadas nas categorias em estudo. 
Tabela 1. Apresentação e caracterização das empresas pesquisadas.

\begin{tabular}{|c|c|c|c|c|c|}
\hline & \multicolumn{3}{|c|}{ Supermercado } & \multicolumn{2}{|c|}{ Indústria } \\
\hline & $\mathbf{A}$ & B & $\mathrm{C}$ & $\mathbf{X}$ & $\mathbf{Y}$ \\
\hline Data da entrevista & $\begin{array}{l}\text { Nov/2001 e meados } \\
\text { de } 2002\end{array}$ & Set/2002 & Mai/2002 & Abr/2002 & Jun/2002 \\
\hline $\mathrm{N}^{\circ}$ de unidades & 1 & 20 & 61 & 12 & - \\
\hline Classificação/m² & Pequeno & Médio & Médio & Líder no setor & Líder no setor \\
\hline $\mathrm{N}^{\circ}$ funcionários & 155 & 3500 & 7500 & 27000 & 13000 \\
\hline Público-Alvo & $\mathrm{A} / \mathrm{B}$ & $\mathrm{C} / \mathrm{D}$ & $\mathrm{A} / \mathrm{B} / \mathrm{C}$ & Todos segmentos & Todos segmentos \\
\hline $\begin{array}{l}\text { Principais } \\
\text { concorrentes }\end{array}$ & $\begin{array}{l}\text { Pão de Açúcar, } \\
\text { Carrefour, Wal-Mart }\end{array}$ & $\begin{array}{l}\text { Carrefour, Extra e } \\
\text { Wal-Mart }\end{array}$ & Pão de Açúcar & $\begin{array}{l}\text { Unilever, Perdigão, } \\
\text { Santista }\end{array}$ & $\begin{array}{l}\text { Para cada segmento em } \\
\text { que atua há uma empresa }\end{array}$ \\
\hline $\begin{array}{l}\text { Variáveis que } \\
\text { influenciam no grau } \\
\text { de fidelização dos } \\
\text { clientes }\end{array}$ & $\begin{array}{l}\text { Qualidade no } \\
\text { atendimento e } \\
\text { qualidade nos produtos } \\
\text { perecíveis }\end{array}$ & $\begin{array}{l}\text { Qualidade no } \\
\text { atendimento e } \\
\text { política de preço } \\
\text { (custos mais baixos) }\end{array}$ & $\begin{array}{l}\text { Qualidade nos } \\
\text { produtos perecíveis, } \\
\text { facilidade de acesso } \\
\text { e pagamento }\end{array}$ & $\begin{array}{l}\text { Qualidade nos } \\
\text { produtos, } \\
\text { diversificação }\end{array}$ & $\begin{array}{l}\text { Qualidade nos produtos, } \\
\text { diversificação }\end{array}$ \\
\hline Projeto Piloto & $\begin{array}{l}1 \text { (iniciativa da } \\
\text { indústria) }\end{array}$ & $\begin{array}{l}1 \text { (iniciativa do vare- } \\
\text { jo) em } 1 \text { loja }\end{array}$ & $\begin{array}{l}5 \text { (iniciativa do } \\
\text { varejo) }\end{array}$ & $\begin{array}{l}1 \text { (iniciativa do } \\
\text { varejo) }\end{array}$ & 1 (iniciativa do varejo) \\
\hline Empresas/parceiras & $\begin{array}{l}\text { - Sadia (Categoria } \\
\text { Lanches) }\end{array}$ & $\begin{array}{l}\text { - Coca-Cola (refri- } \\
\text { gerantes), devido } \\
\text { ao know-how em } \\
\text { pesquisa de mercado } \\
\text { e marca consolidada }\end{array}$ & $\begin{array}{l}\text { - Nestlé (chocolates) } \\
\text { - Spal (refrigerantes) } \\
\text { - Ambev (cervejas) } \\
\text { - Bauducco (biscoitos) } \\
\text { - Sadia (refeições } \\
\text {-congelados) }\end{array}$ & $\begin{array}{l}\text { - Bom-Preço } \\
\text { (Categoria refeições) }\end{array}$ & $\begin{array}{l}\text { - Bom-Preço } \\
\text { (Categorias Láctea e } \\
\text { Biscoitos) }\end{array}$ \\
\hline $\begin{array}{l}\text { Resultados } \\
\text { marcantes da } \\
\text { experiência }\end{array}$ & $\begin{array}{l}\text { Bons resultados } \\
\text { (crescimento nas } \\
\text { vendas em 20\%) }\end{array}$ & $\begin{array}{l}\text { - Não tiveram proble- } \\
\text { mas com a parceria e } \\
\text { nem com os funcioná- } \\
\text { rios, pois os objetivos } \\
\text { do projeto foram bem } \\
\text { esclarecidos } \\
\text { - Obtiveram bons } \\
\text { resultados (nova visão } \\
\text { sobre a própria cate- } \\
\text { goria) e implantação, } \\
\text { expandindo a } \\
\text { metodologia para } \\
\text { outras lojas }\end{array}$ & $\begin{array}{l}\text { - Simplificação } \\
\text { do processo para } \\
\text { facilitar a implanta- } \\
\text { ção para outras lojas } \\
\text { da rede (adaptação } \\
\text { à realidade desta } \\
\text { empresa) }\end{array}$ & $\begin{array}{l}\text { - O projeto foi } \\
\text { finalizado no meio } \\
\text { do processo, por } \\
\text { motivos específicos } \\
\text { do varejista, não } \\
\text { havendo um } \\
\text { resultado final } \\
\text { - Aquisição de uma } \\
\text { prática metodológi- } \\
\text { ca para expandir e } \\
\text { aprimorar outras ca- } \\
\text { tegorias com outros } \\
\text { varejistas }\end{array}$ & $\begin{array}{l}\text { - Bons resultados, } \\
\text { proporcionando nova } \\
\text { visão sobre a própria } \\
\text { categoria e implantação, } \\
\text { expandindo a } \\
\text { metodologia para outras } \\
\text { empresas varejistas }\end{array}$ \\
\hline
\end{tabular}

Fonte: questionários/entrevistas

Enfim, pode-se dizer que é importante ter o envolvimento da alta direção, a clara definição de responsabilidades, o conhecimento das ferramentas pelos envolvidos no processo, o suporte dado pela estrutura organizacional nas análises dos dados, a orientação para resultados e o desenvolvimento e treinamento intensivo de pessoal.

\section{b) Tecnologia de Informação}

O GC está baseado no uso intensivo de tecnologia da informação, e o desafio para este processo reside na amplitude e na profundidade dos dados a serem analisados e na variedade de análises necessárias, por isso as indústrias entrevistadas têm que ter sistemas internos desenvolvidos (softwares específicos) para armazenar, analisar e consolidar esses dados em relatórios.

Em contrapartida, para as empresas varejistas, a automação comercial dos PDVs é considerada básica para iniciar um sistema de GC. Essas empresas também devem apresentar algumas tecnologias de informação (EDI, internet, softwares aplicativos de desenvolvimento dos planos e de análises das categorias), para facilitar o contato e minimizar os custos entre as empresas parceiras, agilizando o processo de análise para tomada de decisão.

\section{c) Estratégia}

Por ser o GC um processo estratégico, há uma necessidade de os procedimentos, os recursos, e as metas para as categorias serem traçados entre a diretoria e os gerentes executivos responsáveis pela gestão das unidades de negócios, tanto da indústria quanto do varejo, sendo, posteriormente, difundidos para o setor de compras e todo o corpo operacional dos supermercados. Dentro desse contexto, é válido destacar que os funcionários que trabalham diretamente com o reposicionamento dos produtos nas gôndolas devem entender o 
objetivo principal da implementação do GC nas lojas e seus benefícios, para que não haja uma certa resistência e acabem não realizando os procedimentos corretos para um eficiente resultado. Para tanto, é necessário, segundo entrevistados, treinamento interno, principalmente, sobre planograma.

Como o GC tem o objetivo de gerenciar cada categoria como unidades de negócios, cada unidade deverá ter seus objetivos com ações internas e metas estabelecidas, acompanhadas pelo cartão de metas, que abrangem medidas de desempenho internas e externas e da categoria. No presente trabalho, não foram reveladas metas quantitativas por categoria, mas, sim, decisões a longo prazo referentes a esse processo, visando a oferta de "valor" aos consumidores, por meio do comprometimento da alta direção e da definição de estratégias corporativas vinculadas a estratégias das categorias.

\section{d) Processo}

O processo de negócio deve estar de acordo com as estratégias departamentais/divisionais e corporativas do varejista e do fornecedor, e deve estimular o aprimoramento contínuo por monitoramento constante dos dados e planos das categorias.

A metodologia adotada para implementação do GC, de forma geral, pelas empresas varejistas está concentrada nas etapas de análise de dados internos e externos de categorias com os compradores, definição de papel, estratégias, táticas para as categorias, definições das promoções e implantação nas lojas e acompanhamento. Já as indústrias entrevistadas estão adotando uma metodologia de forma mais enxuta com três reuniões importantes: a primeira para afirmar o comprometimento (início) e validação da categoria, a segunda para avaliação da categoria (com a troca dos dados) e a última para pré-definição de estratégias e táticas, amarrando a implementação.

Além do estabelecimento dessas etapas, é importante analisar a relação "custo $\mathrm{x}$ benefício", avaliando o montante investido na implementação dessa ferramenta e seus benefícios quanto às mudanças internas e externas (analisando a relação empresa $x$ mercado $x$ concorrentes), bem como determinar os índices de desempenho para um melhor acompanhamento do GC e da evolução (\%) do processo de avaliação dessa categoria. As empresas analisadas, geralmente, estão adotando faturamento, vendas e ticket médio como índices de desempenho para avaliar as categorias.

\section{Conclusões}

Como já discutidas no início deste artigo, as razões de mercado que deram início à mudança de uma postura de relacionamento mais próximo e cooperativo, visando um posicionamento estratégico para se manter competitivo no mercado, são consideradas razões não específicas a uma empresa, mas sim que compõem o ambiente competitivo atual, influenciando igualmente todas as empresas que nele atuam, incluindo as empresas não pesquisadas. Portanto, pode-se considerar que as ações já realizadas pelas empresas em questão devem ser visualizadas como alternativas na busca de uma situação mais favorável, quando comparada a dos concorrentes.

Paralelo a apresentação dos componentes-chave para implementação do GC nas pequenas e médias empresas supermercadistas, as etapas a serem desenvolvidas nesse processo, suas características facilitadoras e limitadoras, os critérios de escolha do parceiro e a análise dos benefícios advindos do GC para a eficiência na gestão da cadeia de suprimentos, compõem os pontos apresentados a seguir.

\section{As etapas a serem desenvolvidas:}

1) Procurar entender profundamente a utilidade da ferramenta de gestão, sua funcionalidade, conhecendo a sua essência, seus benefícios, e dificuldades de implementação; buscando conciliar com a visão clara dos objetivos da empresa;

2) Conscientizar os membros da empresa (diretores, gerentes e funcionários) sobre a operacionalização e necessidade do GC no alcance dos objetivos da empresa para, então, posteriormente, focar os esforços na otimização dos processos internos;

3) "Arrumar a casa", ou seja, preparar-se internamente em relação aos aspectos tecnológicos, humanos e estratégicos, pois a implementação do GC exige uma estrutura interna adequada. Nesse sentido, as empresas devem analisar o estágio atual das tecnologias e a sua disponibilidade, identificando, assim, a necessidade de adaptações e trocas de sistemas, além da realização de treinamentos para seus funcionários;

4) Procurar conhecer profundamente o parceiro potencial, para entender como funciona seu processo de negócio, e analisar seus interesses, considerando, sempre, seu knowhow na área e sua infra-estrutura tecnológica;

5) Procurar valorizar a estrutura e o valor que o parceiro pode adicionar ao negócio;

6) Realizar projetos-piloto, como forma de adquirir experiência e avaliar os ganhos, as dificuldades encontradas com a implementação da ferramenta GC. Para tanto, é necessário o acompanhamento e o cumprimento de todas as etapas estabelecidas no acordo da parceria; $\mathrm{e}$

7) Buscar mecanismos para alavancar a confiança mútua entre as empresas parceiras, quando da adoção de projetospiloto ou de implementação mais evoluída de um processo de GC, definindo seus papéis e suas funções no contexto do GC, compartilhando informações entre as partes e confiando nos dados fornecidos pelos parceiros.

\section{As características facilitadoras:}

1) Uma postura participativa da alta direção na incorporação dessa ferramenta na empresa, uma vez que as decisões e o estabelecimento de metas para a efetividade do GC exige tomada de decisões, e, conseqüentemente, o envolvimento da alta direção das organizações;

2) O uso da tecnologia de informação; 
3) A definição de atividades afins direcionadas a pessoas dedicadas à adoção e acompanhamento da ferramenta;

4) A existência da compreensão e da sinergia entre a estratégia e a cultura organizacional das empresas envolvidas, para que as atividades-chave sejam realizadas sem problemas;

5) A flexibilidade e adequação da metodologia de acordo com a realidade da empresa varejista, sem perder a essência do processo; e

6) No caso de pequenos e médios supermercados, um histórico positivo de casos bem sucedidos quanto à implementação da ferramenta.

\section{As características limitadoras:}

1) A falta de conhecimento e entendimento, principalmente por parte das pequenas e médias empresas varejistas, sobre os ganhos dessa ferramenta, está relacionado, geralmente, à dificuldade de entender as análises e disponibilizar os recursos exigidos pela metodologia "padrão" (8 etapas) utilizada pelo ECR Brasil;

2) O trabalho de implementação é relativamente longo para os iniciantes, e requer alto investimento de recursos e de pessoas. Essa idéia pode fortalecer a imagem de ser um processo restrito às grandes organizações; e

3) A resistência existente às mudanças necessárias, advinda de uma cultura organizacional mais tradicional ou de vários anos.

\section{Os critérios de escolha do parceiro:}

1) Do lado da indústria, o parceiro deve estar consciente e disposto a mudanças, além de ter uma participação efetiva nas reuniões e negociações; as empresas parceiras devem ser automatizadas e dispor de informações de mercado e base de dados coerentes, bem como ser uma organização com um posicionamento estratégico bom no local em que atua;

2) Do lado do varejo, as indústrias devem ter um conhecimento acumulado sobre a implementação da ferramenta GC; estar disposta a investir na categoria gerenciada e ter mais agilidade na implementação, na medida em que as decisões são tomadas nas reuniões acordadas; e

3) De maneira geral, as empresas devem trabalhar em conjunto com uma visão de negócio de médio e longo prazo, com o objetivo de identificar oportunidades e resolver os problemas.

Quanto aos benefícios advindos do GC, estes podem influenciar positivamente no processo à montante da cadeia por ser um processo que exige uma aproximação mais colaborativa entre fornecedores e varejistas, no sentido de desenvolvimento de produtos e de técnicas de vendas. Acredita-se que com um melhor trabalho de promoção dos produtos nas gôndolas e com o oferecimento de produtos mais adequados, definidos com base em pesquisas de mercado feitas junto aos consumidores finais, é possível aumentar a frequiência e a quantidade da compra e, conseqüentemente, desencadear todo um processo de produção para suprir essa cadeia. Para tanto, essa ferramenta exige a adoção de tecnologias de informação como suporte para análise interna da categoria e tomada de decisão, bem como para uma comununicação mais próxima, mais rápida e menos onerosa em relação aos custos operacionais.

Por outro lado há, ainda, algumas dificuldades a serem superadas, como a resistência das pessoas envolvidas no processo em relação à difícil manutenção dos planos e acompanhamento constante dos dados e das estratégias, a falta de organização dos dados por parte dos varejistas, o pessoal desqualificado para operação em loja.

Entretanto, pelo tipo de pesquisa realizada, não se pode generalizar os benefícios e as dificuldades encontradas na implementação da ferramenta para todos os casos do setor, pode-se verificar um esforço contínuo das redes supermercadistas em busca da eficiência operacional e da otimização dos processos na cadeia de suprimento, destacando-se a determinação dessas empresas em se prepararem para uma nova realidade de maior concorrência. Para isso estão procurando trabalhar em conjunto com fornecedores no sentido de proporcionar maior eficiência a toda cadeia de suprimento e maior valor ao consumidor final, isso até por uma questão de simples sobrevivência no mercado.

\section{Agradecimentos}

Agradecemos à Fundação de Amparo a Pesquisa do Estado de São Paulo (FAPESP), órgão financiador do $1^{\circ}$ autor deste artigo.

\section{Referências Bibliográficas}

ALCANTARA, R. L. C. A gestão estratégica dos canais de distribuição: um exame da evolução e do atual estágio do relacionamento entre o atacado de entrega e a indústria. São Paulo, 1997. 194 f. Tese (Doutorado em Administração). Escola de Administração de Empresas de São Paulo, Fundação Getúlio Vargas.
ARAVECHIA, C. H. M.; PIRES, S. R. I. Gestão da cadeia de suprimentos e avaliação de desempenho. In: ENCONTRO ANUAL DA ASSOCIAÇÃO DE PÓS-GRADUAÇÃO EM ADMINISTRAÇÃO (ANPAD), 24., 2000, Florianópolis. Anais...Florianópolis, 2000

BATALHA, M. O; SILVA, A. L. da. Gerenciamento de siste- 
mas agroindustriais: definições e correntes metodológicas. In: BATALHA, M. O. (Coord.). Gestão Agroindustrial. São Paulo: Atlas, 2001. v. 1, cap. 1, p. 23-63.

BERRY, L. O Modelo Emergente. HSM Management, ano 3, n. 13, p. 58-64, mar.-abr., 1999.

BOWERSOX, D. J; CLOSS, D. J. Logistical management: the integrated supply chain process. New York: McGrawHill, 1996.

CATEGORY MANAGEMENT: The Category Plan. FMI and Center for Retail Management: Northwestern University, 1995.

CESARINO, R. C.; CAIXETA FILHO, J. V. Alocação dos produtos nas gôndolas dos supermercados: um estudo de caso. Gestão e Produção, v. 9, n. 1, p. 45-61, abr. 2002.

CHAPMAN, P. et al. Building Internet capabilities in SMEs. Logistics Information Management, v. 13, n. 6, p. 353-360, 2000.

COOPER, M. C.; LAMBERT, D. M.; PAGH, J. D. Supply chain management: more than a new name for logistics. The International Journal of Logistics Management, v. 8, n. 1, p. 1-13, winter, 1997.

DESMET, P.; RENAUDIN, V. Estimation of product category sales responsiveness to allocated shelf space. International Journal of Research in Marketing, v. 15, p. 443-457, 1998.

DIB, J. A. Efficient Consumer Response (ECR): Uma Estratégia para o Varejo de Bens de Consumo de Massa. Revista de Administração. São Paulo, v. 32, n. 2, p. 14-22, abr.-jun. 1997.

ECR BRASIL. Pricewaterhouse Coopers (Cood.). Gerenciamento por Categorias: melhores práticas. São Paulo: Associação ECR Brasil, 1998.

Gerenciamento por Categoria: Guia de informações, 7. São Paulo: Associação ECR Brasil, 2000.

Integration Consultoria Empresarial (Coord). Treinamento prático de gerenciamento por categoria. São Paulo: Associação ECR Brasil, setembro, 2001.

FARINA, E. M. M. Q.; ZYLBERSZTAJN, D. Competitividade no Agribusiness Brasileiro: introdução e conceitos. São Paulo: PENSA/FIA/FEA - USP, v. 1, 1998.

FIGUEIREDO, R. S; ZAMBOM, A. C. A empresa vista como um elo da cadeia de produção e distribuição. Revista de Administração da USP. São Paulo, v. 33, n. 3, p. 29-39, jul.-set., 1998.

FLEURY, P. F. Supply Chain Management: conceitos, oportunidades e desafios da implementação. Revista Tecnologística, ano 4, n. 30, p. 25-32, fev. 1999.

GHISI, F. A. A implementação do ECR (Efficient Consumer Response) no canal de distribuição de produtos de mercearia básica: um estudo multicaso, 2001. 127 f. Dissertação (Mestrado em Engenharia de Produção). Departamento de Engenharia de Produção, Universidade Federal de São Carlos, São
Paulo, 2001.

HARRIS, J. K.; SWATMAN, P. M. C., KURNIA, S. Efficient Consumer Response (ECR): a survey of the Australian grocery industry. Supply Chain Management, v. 4, n. 1, p. 35-42, 1999.

HOBAN, T. J. Food industry innovation: efficient consumer response. Agribusiness, v. 14, n. 3, p. 235-245, 1998.

HOGARTH-SCOTT, S. Retalier-supplier partnerships: hostages to fortune or the way forward for the millennium? British Food Journal, v. 101, n. 9, p. 668-682, 1999.

HOGARTH-SCOTT, S.; DAPIRAN, G. P. Shifting category management relationships in the food distribution channels in the UK and Australia. Management Decision, v. 35, n. 4, p. 310-318, 1997.

HUTCHINS, R. Category management in the food industry: a reserch agenda. British Food Journal, v. 99, n. 5, p. 177-180, 1997.

HUTT, M. D; SPEH, J. W. Supply Chain Management. Business Marketing Management: a strategic view of industrial and organizational markets.7 ed. USA: Harcourt College Publishers, 2001.

KING, R. P; PHUMPIU, P. F. Reengineering the food supply chain: the ECR initiative in the grocery industry. American Journal of Agricultural Economics, v. 78, p. 1181-1186, dec. 1996.

KINSEY, J.; ASHMAN, S. Information technology in the retail food industry. Technology in Society, v. 22, p. 83-96, 2000.

KOTZAB, H. Improving supply chain performance by efficient consumer response? A critical comparison of existing ECR approaches. Journal of Business \& Industrial Marketing, v. 14, n. 5-6, p. 364-377, 1999.

KUMAR, N. The revolution in retailing: from market driven to market driving. Long Range Planning, v. 30, n. 6, p. 830-835, 1997.

KURNIA, S.; SWATMAN, P. M. C.; SCHAUDER, D. Efficient Consumer Response: a preliminary comparison of US and European experiences. $\mathbf{1 1}^{\text {th }}$ International Conference on Eletronic Commerce, Bled, Slovenia, p. 126-143, jun. 1998.

KURNIA, S.; JOHNSTON, R. B. Adoption of efficient consumer response: the issue of mutuality. International Journal of Supply Chain Management, v. 6, n. 5, p. 230-241, 2001.

MARQUES, E. F. Gerenciamento por Categorias: um estudo multicaso em pequenas e médias empresas supermercadistas. 2003. 135 f. Dissertação (Mestrado em Emgenharia de Produção). Departamento de Engenharia de Produção, Universidade Federal de São Carlos, São Paulo, 2003.

MOREIRA, C. M. Estratégias de reposição de estoques em supermercados: avaliação por meio de simulação. 2001. 134f. Dissertação (Mestrado em Engenharia de Produção). Departamento de Engenharia de Produção, Universidade 
Federal de Santa Catarina, Florianópolis, 2001.

PORTER, M. E. Estratégia competitiva: técnicas para análise de indústrias e da concorrência. Rio de Janeiro: Ed. Campus, 1986.

ROJO, F. J. C. Gerenciamento por categorias: estudo de caso. I Prêmio ECR de Pesquisa, 2001.

SALMON, K. ASSOCIATES. Efficient Consumer Response. Enhancing consumer value in the grocery industry. Washington, DC, jan. 1993.

SEGRE, L. M.; BASTOS, R. M. Modernização produtiva nos supermercados: a adoção de tecnologias de informação e comunicação. Revista de Administração, São Paulo, v. 35, n. 4, p. 72-83, out.-dez. 2000.

SILVA, A. L. da. A adoção de tecnologia de informação em canais de distribuição: um estudo multicaso na utilização de EDI entre varejo e indústria agroalimentar. 1999. 155 f. Tese (Doutorado em Administração). Faculdade de Economia, Administração e Contabilidade, Universidade de São Paulo, São Paulo, 1999.
SILVA, A. L. da; FISCHMANN, A. A. Impacto da tecnologia de informação no Supply Chain Management: um estudo multicaso sobre a adoção de EDI entre varejo e indústria agroalimentar. Gestão \& Produção, São Carlos, v. 6, n. 3, p. 201-218, dez. 1999.

STERN, L.; EL-ANSARY, A. I. Marketing Channels. 4. ed. New Jersey: Prentice Hall, 1992.

SVENSSON, G. The theoretical foundation of supply chain management: A functionalist theory of marketing. International Journal of Physical Distribution \& Logistics Management, v. 32, n. 9, p. 734-754, 2002.

WOOD JR., T. Supply Chain Management: um conceito para aumentar a competitividade das empresas latino-americanas. In: BUSINESS ASSOCIATION FOR LATIN AMERICAN STUDIES (BALAS), 17.,1998, South Padre Island. Anais... South Padre Island, USA, 1998.

ZILBER, M. A., FISCHMANN, A. A. Mudanças na distribuição: o papel da estratégia. In: SEMINÁRIOS EM ADMINISTRAÇÃO (SEMEAD), 4., 1999, São Paulo. Anais... São Paulo, out.1999.

\title{
USING THE CATEGORY MANAGEMENT TOOL IN SUPPLY CHAIN MANAGEMENT: A MULTICASE STUDY
}

\begin{abstract}
In today's highly competitive scenario, the industrial and retail sectors seek alternatives to ensure their continuity in the Brazilian market. To meet consumer expectations, one of the alternatives these sectors have devised is to offer a mix of products tailored to the profile of each group of customers. Within this context, the Category Management (CM) tool and other Efficient Consumer Response (ECR) practices have begun to take hold in the daily routine, culture and strategies of companies. To illustrate how the CM can be an efficiency-optimizing tool in supply chain management, this article discusses the main actions to be developed in the implementation of this tool in small and medium sized supermarkets, its facilitating and limiting characteristics, and criteria for the choice of business partners.
\end{abstract}

Keywords: Supply Chain, distribution channels, ECR, Category Management, small and medium sized supermarkets. 